\title{
A EXPERIÊNCIA DO ESTUDANTE DE GRADUAÇÃO DE ENFERMAGEM NA ESCOLA DE 1\% GRAU PRESTANDO ASSISTÊNCIA PRIMÁRIA DE SAÚDE
}

\author{
Espreafico, Enilza M. * \\ Lourenço, Maria Regina *
}

$\operatorname{ReBEn} / 08$

ESPREAFICO, E. M. e Colaboradora - A Experiência do Estudante de Graduação de Enfermagem na Escola de 19 Grau Prestando Assistência Primária de Saúde. Rev. Bras. Enf.: RS, 36: $72-94$, 1983.

\section{RESUMO}

O trabalho analisa a experiência de 43 dos 65 estudantes que cursam o 50 semestre de graduação de 1982 da Escola de Enfermagem da USP, Campus Ribeirão Preto, atuando em uma escola de 1 o grau, localizada na periferia de Ribeirão Preto, constituída por alunos do bairro de nível sócioeconômico precário prestando assistência de saúde ao escolar, através de seu meio-ambiente: escola, família e comunidade. questões.

Para avaliar a experiência desses estudantes, utilizamos um questionário constando de 18

A análise dos resultados traduz a importância de se incluir programas semelhantes nos currículos de graduação de Enfermagem, significando aprendizado, conscientização dos estudantes e abertura de campo de atuação do enfermeiro.

\section{INTRODUÇÃO}

Desde que o homem vive em sociedade a enfernagem é praticada, porém, se já nos primórdios parte de sua assistência se voltava à Saúde Pública, com o progresso dos conhecimentos científicos, revolução industrial, aumento de hospitais e equipamentos sof isticados ela volta-se predominantemente à assistência curativa, o que num país subdesenvolvido como o Brasil não tem valor para amenizar os problemas de saúde facilmente preveníveis.

Sabe-se, entretanto, que a higiene principalmente infantil, eram consideradas de grande valor, já em era muito longínqua, como entre os antigos egípcios.

Muito posteriormente Furtembach em seu livro publicado em 1649 relata experiências referentes às casas-escolas e suas instalações, zelando por melhores condiçőes higiênicas.

No século XVIII, Joham Peter Frank realizou eminentes trabalhos referentes à saúde pública e fazia denúncias sobre a miséria dos povos e apelos ao seu combate, pois representava fontes de doenças e morte. Preconizou a "higiene escolar", estabelecendo conjuntos de normas e medidas higiênicas para aplicação nas escolas.

\footnotetext{
* Estudantes do 5 9 semestre de graduação da Escola de Enfermagem de Ribeirão Preto USP
} 
ESPREAFICO, E. M. e Colaboradora - A Experiência do Estudante de Graduação de Enfermagem na Escola de 19 Grau Prestando Assistência Primária de Saúde. Rev. Bras. Enf.: RS, 36: $72-94$, 1983.

Somente vários anos após, surgiu a necessidade da vigilância sanitária do escolar e, mais recentemente a partir de 1918, percebeu-se a importância de, na assistência ao escolar, envolver e considerar todos os fatores ligados e que sobre ele influem, contrapondo a sua saúde, tais como baixo nível sócio-econômico cultural do país, desemprego, promiscuidade dos lares, vícios, abandono, etc.

Por muito tempo e ainda hoje, os currículos de graduação da maioria das escolas de enfernnagem privilegiam a assistência secundária, ou seja, hospitalar, restringindo-se basicamente à prática de saúde pública nas escolas brasileiras, ao que se chama de habilitação, incluída no 4 ? ano de graduação de forma facultativa, na qual, como alternativa de opção, está a saúde pública.

Considerando-se o contexto social, econômico e político do Brasil e as condições de vida da população inserida neste contexto, principalmente a população infantil, pois é a criança a vítima direta de todos os "males sociais" devido a sua maior fragilidade e peculiaridades nutricionais, estão ultimamente algumas escolas de enfermagem, ou setores delas, voltando-se mais autenticamente, à saúde pública em geral e especificamente à saúde escolar, o que além de "prover benefícios" à sociedade também o faz à classe profissional tendo em vista ser uma área onde o enfermeiro pode atuar com maior autonomia.

Desenvolver o padrão de vida da criança brasileira é tarefa notável para o profissional de saúde, só uma participação consciente e ativa sobre os problemas do povo e do país, poderá trazer algum resultado positivo.

$\mathrm{Na}$ fase escolar, época em que a criança apresenta-se muito suscetível ao aprendizado e sofre diversas transfornações de ordem social psicológica e adaptativa, deve-se dar ênfase à educação em saúde.

\section{A SITUAÇĀO DA CRIANÇA NO BRASIL}

O Centro de Defesa da Qualidade de Vida no livro editado em janeiro de 1980 expõe, sob forma de questionamento a situação atual: "A que conclusão pode-se chegar quando se sabe que $83 \%$ da população infantil do país sof re de desnutrição crônica, que 14 milhões de menores moram em barracos ou simplesmente não tem onde morar; que a cada hora morrem 45 crianças de até um ano; que no Brasil há 12 milhões de crianças sem escolas; que milhões de crianças trabalham desde os 5 ou 6 anos de idade; que há no país mais de 15 milhões de menores carentes e abandonados e que são formados "esquadrões da morte" contra crianças delinqüentes, considerados como a "última palavra" para se "resolver" os efeitos sociais mais dramáticos da situação exposta acima? Qual a única conclusão que se pode tirar? A de que é de absoluta miséria, degradação humana, de exploração e opressão as condições de vida da esmagadora maioria das crianças brasileiras. Como solucionar esses problemas nos "marcos" da repressão policial contra menores abandonados, do regime das multinacionais, dos latifúndios e do arrocho salarial? (Centro de Defesa da Qualidade de Vida, 1979).

A educação elementar sof re seletividade acentuada em razão da distribuição seletiva de renda mas também por fornas "latentes" de seletividade intra-escolar, resultando em reprovações, atrasos e evasões. Desde 1942, quando a concentração de renda não era tão acentuada, até hoje a evasão escolar ocorrida da 1 a para a 2 a série se mantém em torno de quase $60 \%$, estes excluídos das escolas, possivelmente se transformam em mão de obra desqualificada e marginalizada ou vão se arrastando atrasadas pelas diversas séries. (Melo 1981).

As diversas escolas da rede oficial de ensino, distribuídas no país, mais claramente as da periferia limitam-se essencialmente a of erecer ao aluno o ensino escolar restrito às exigências curriculares, quando se faz indispensável à educação a inclusão de uma sistemática de programações outras, como; culturais, artísticas e variada prática desportiva e de lazer.

\section{PREPARO DO ENFERMEIRO PARA SAÚDE ESCOLAR}

Diante de toda problemática social, está o profissional de enfermagem, juntamente com outros profissionais correlatos com uma incumbência, difícilima mas importantíssima luta pela promoção da saúde. Sendo assim, "vê-se" o enfermeiro, como profissional eminentemente educador e, portanto, sente a necessidade de ampliar seu campo de atuação de modo a não só conhecer criticamente a realidade social como tentar modificá-la.

Realizar um programa de saúde junto ao escolar significa organizar uma metodologia e aplicá-la por meio de atividades simples de forma a "assegurar" ao aluno a formação de conceitos e princípios básicos de saúde.

A educação em saúde deve abranger todos os aspectos da vida escolar e deve estar integrada a educação global e ser compatível com a situação sócio-econômica e sanitária do país. 
ESPREAFICO, E. M. e Colaboradora - A Experiência do Estudante de Graduação de Enfermagem na Escola de 19 Grau Prestando Assistência Primária de Saúde. Rev. Bras. Enf.: RS, 36: $72-94$, 1983.

A escola, como instituição educacional e como meio integrante da comunidade, tem importante papel na melhoria da qualidade de vida da sociedade na qual se insere. Porém, - o nível de desenvolvimento dessa sociedade $\mathrm{e}$ as condições concretas de existência que ela of erece às suas diferentes frações de classe, impõe limites à atuação tanto da escola quanto de qualquer programa de educação e ou de saúde.

Pela importância da saúde escolar e seu completo desenrolar nos últimos tempos, fazse mistér a preparação mais específica dos profissionais de saúde, através de disciplinas apropriadas para que, conscientemente, possam executar as atribuições referentes à educação e saúde social do escolar.

Em relação ao enfermeiro, esse preparo é uma realidade em alguns países, como os Estados Unidos. Um programa de saúde escolar é a combinação de muitas atividades inter-relacionadas que compreendem educação sanitária, serviços de saúde escolar, serviços de proteção do ambiente escolar e outros. $\mathrm{O}$ enf ermeiro escolar deve assumir a maior parte das responsabilidades do programa de saúde e trabalhar em colaboração com outros profissionais na escola e na comunidade. (Oda, 1977)

Nestes locais os enfermeiros escolares estão se preparando para of erecer atenção primária de saúde mediante a evolução de problemas físicos, psiquiátricos, psíquico-educacionais, de comportamento e de aprendizagem e para dar atenção integral à criança sã. Também tem que estar atento para com o desenvolvimento do programa de saúde posto em prática. (Silver 1971, Apud in Oda 1977)

Considerando-se a subnutrição crônica, tanto pela gravidade de seus efeitos como pela gravidade do número de crianças que atinge, constata-se que o enfermeiro escolar deve receber em sua formação uma grande bagagem de conhecimentos referentes aos aspectos nutricionais, podendo elaborar ou adaptar planos efetivos de suplementação alimentar, que, se não resolver o problema, pelo menos o ameniza quando bem estruturado e aplicado. O que ocorre no Brasil é que a merenda é distribuida, já "preparada" às escolas, constituídas predominantemente de hidratos de carbono; apresenta sabor incompatível com os "costumes" brasileiros, fazendo-se alta a freqüência de rejeição pelas crianças e, muitas vezes, são detectados alimentos deteriorados em via de utilização.

Como demonstrou o departamento de Ecologia Humana da Universidade Del Valle (Cali, Colômbia), quando se associa a suplementação alimentar adequada e a estimulação afetiva e social sob a forma de uma atividade regular e coordenada, apoiada em uma estrutura estável do tipo pré-escola ou parque infantil, é perfeitamente viável aproximar o desenvolvimento mental e o desempenho escolar das crianças do extrato sócio-econômico mais baixo aos níveis alcançados por seus iguais mais favorecidos.

Implica aqui mencionar também, os graves problemas de infecções e parasitoses que freqüentemente estão associados à subnutrição e baixo nível sócio-econômico e, portanto, fazendo-se mistér ao enfermeiro conhecer e combater esses fatores.

Em síntese, os requisitos para o preparo do enfermeiro escolar seriam a inclusão de matérias que tratem dos seguintes aspectos:

- psicologia da educação;

- fundamentos da educação;

- currículo e métodos de ensino,

- psicologia da criança e do adolescente,

- fisiologia do crescimento e do desenvolvimento da criança e do adolescente,

- saneamento da escola e epidemiologia,

- pediatria,

- estatística de saúde,

- guias e aconselhamentos sobre crianças excepcionais;

- princípios e práticas de Enfermagem de Saúde Pública;

- princípios de organização e administração de Saúde Pública;

- princípios de educação física,

- serviços de nutrição em escolas públicas,

- princípios de administração de escolas públicas,

( Lois Frels, junho 1974 \& Stoffell, junho 1974)

\section{RELATO DE UMA EXPERIÊNCIA}

Ao iniciar o curso de Enfermagem Pediátrica no 10 semestre de 1982 para o 39 ano de graduação da Escola de Enfermagem da USP de Ribeirão Preto, foi proposto pelas docentes da disciplina, MARIA DAS GRAÇAS FERRIANI e MARIA APARECIDA TEDESCHI CANO, um Programa de Saúde Escolar (anexo 1), ocupando 2 semanas, ou seja 80 horas da carga horária do curso, constan- 
ESPREAFICO, E. M. e Colaboradora - A Experiência do Estudante de Graduação de Enfermagem na Escola de 10 Grau Prestando Assistência Primária de Saúde. Rev. Bras. Enf.: RS, 36: $72-94$, 1983.

te de algumas aulas teóricas e estágios práticos. O programa deveria ser desenvolvido pelos estudantes com apoio e acompanhamento de um dos docentes responsáveis, no decorrer do período letivo do semestre referido, sendo de duas semanas consecutivas o período de atuação de cada turma que constitui a classe.

Foram expostos à classe os principais objetivos do programa que visavam, mostrar aos estudantes a realidade social da população brasileira, particularmente a do escolar; prover lhes experiências novas, fora do âmbito hospitalar; mostrar-lhes as condições de crescimento, desenvolvimento (físico e intelectual) e nutrição da criança escolar; dar-lhes oportunidade de interagir com o sistema escolar (crianças, fam ́lias, e comunidade) e mostrar um "novo" campo de atuação do enfermeiro.

O programa foi desenvolvido, conforme o exposto acima, em uma escola de 10 grau da periferia de Ribeirão Preto, constituída por 700 alunos, moradores do bairro, a grande maioria de nível sócioeconômico precário.

O programa abrangeu de forma integral apenas as 1 ạs e 2 a s séries, que totalizam aproximadamente 300 alunos distribuídos entre os períodos da manhã e da tarde. Com essas crianças foram cumpridas todas as atividades que constam do programa (anexo 1).

Ás 3 ăs e 4 ạs séries foi dada uma assistência parcial, ou seja, excluiu-se exame físico das crianças, anamnese, visita domiciliar e conseqüente relatório das condições familiares.

Explica-se o maior enfoque dado às 1 a s e 2 as séries pela maior vulnerabilidade das crianças aos problemas psicológicos, sociais e adaptativos, maior susceptibilidade ao aprendizado e maior número de crianças "carentes" tendo em vista a evasão escolar e a maneira como se dá, em geral atingindo as crianças de nível sócio-econômico mais precário. Realmente, através da atuação na escola percebemos quão e freqüente é a evasão e deserção escolar.

Através de comentários dos estudantes de Enfermagem durante e após a realização do estágio prático, poderíamos a té inferir que a experiência estava sendo válida. E claro que há de considerar-se, a situação em que decorreu a execução do programa, não havia nenhum apoio financeiro específico, os instrumentos de lazer, esportes e mesmo aqueles utilizados por ocasião de curativos eventuais ou exame físico das crianças eram raros, todos adaptados e alguns inclusive of erecidos pelos próprios estagiários.

Nós, autores deste trabalho, na condição de estudantes participantes e também monitoras voluntárias da disciplina, dispendemos mais tempo e dedicação com esse programa do que os demais alunos, pois em prol dele cumprimos 40 horas mensais de monitoria, divididas entre os diversos períodos da tarde, juntamente com mais 5 outras monitoras.

\section{OBJETIVO E JUSTIFICATIVA:}

O objetivo global deste trabalho é o de avaliar a experiência relatada acima. Tal objetivo foi despertado devido nosso interesse pela formação de enfermeiros conscientes quanto à problemática social e suas conseqüências sobre a criança e o ensino, e portanto, aptos a atuar neste contexto inseridos à saúde escolar.

\section{MATERIAL E MÉTODO:}

Com o fim de atingirmos o objetivo do trabalho, isto é, a avaliação da experiência de educação e saúde escolar adquirida pelos estudantes de enfermagem do 5 9 semestre de graduação, utilizamos um Questionário (anexo 2), constando de 18 questões do tipo abertas e fechadas (com diversos itens inerentes) relativas às atividades realizadas durante o estágio, a ser respondido pelos 65 estudantes que constituem a classe.

\section{RESULTADOS E DISCUSSŌES:}

Obtivemos resposta de apenas 43 estudantes $66,15 \%$, o que se justifica talvez pela ocasião em que ele foi aplicado, ou seja, ocasião de férias, após o término da última prova do período letivo do semestre. Isso pode confirmar, o que já é muito discutido no meio universitário: o estudante apresenta interesse pelas atividades estritamente acadêmicas: cumpridas suas obrigações curriculares, não tem "mais nada" a fazer.

A tabela I mostra que $12 \%$ dos estudantes já haviam experimentado trabalhos em escolas, porém estes trabalhos quando se referem a assistência de saúde foram realizados de forma suscinta, sem continuidade ou não sistematizada. Analisando o grau de dificuldade desses alunos quanto a reali- 
ESPREAFICO, E. M. e Colaboradora - A Experiência do Estudante de Graduação de Enfermagem na Escola de 10 Grau Prestando Assistência Primária de Saúde. Rev. Bras. Enf.:RS, 36: 72-94 , 1983.

zação das atividades do programa, parece-nos que trabalho assim, além de não produzir benefícios efetivos à comunidade também não o fazem aos estudantes.

Sempre que se propõe um programa a ser oficialmente cumprido pelos estudantes como parte integrante do currículo escolar, deve-se ter muito bem traçado os objetivos e, logicamente, aqueles que of ereçam subsídios importantes à formação profissional.

A sociedade e a natureza encontram-se em contínuo processo de desenvolvimento, os conhecimentos a cada dia se ampliam e o moderno a cada instante é ultrapassado. Dentro dessa realidade, continua a escola de Enfermagem, como aliás a maioria das instituições escolares, inabaláveis em seus conceitos, estrutura e metodologia, sem perceber as mudanças do mundo contemporâneo. Esquecendo-se que alguns de seus fundadores, como no caso da enfermagem, Florence Nightingale, foram revolucionários no seu tempo.

Pensamos que um aspecto importante da formação profissional e do ensino em geral é o constante "feedback" entre docentes, estudantes e diretores para que possa haver reformulação e renovação e não simplesmente eliminação de conceitos ultrapassados.

Vários dados contidos nas tabelas II, III e IV revelam que grande parte dos objetivos foram alcançados pelos estudantes, porém não se pode desprezar a pequena porcentagem que foge à regra, seria questão de nova investigação buscar explicações concretas sobre o porquê do não alcance, por esse estudantes dos objetivos esperados.

Pela nossa atuação permanente neste programa podemos a té expor aqui algumas possíveis razões determinantes de tal fato, como a precária formação do estudante em saúde pública associado a sua pequena capacidade crítica, explicada facilmente pelo esquema de ensino a que ele vem sendo submetido, o que a maneira de um ciclo, determina o seu desinteresse para com os aspectos referidos de Saúde Pública.

Por outro lado, poderia considerar-se o próprio desestímulo do aluno face aos precários recursos da comunidade e recursos econômicos para o projeto e ou preparação deficiente do aluno para "enf rentar" os problemas.

Um dado significativo revelado pela tabela II é o referente a "formação profissional" em que quase $42 \%$ dos alunos responderam negativamente, o que ocorre de forma geral, o, estudante ao findar determinado estágio não se sente apto, seguro, com autonomia e liderança suficiente para tomar responsabilidade de cargo semelhante.

Nós, como monitoras, tendo passado mais tempo no programa, podemos dizer que estamos mais aptas para desenvolver com certa autonomia programas semelhantes, e concluímos que subordinado a duas ou três semanas de estágios, com certeza não a teríamos; porém é até mesmo surpreendente um resultado de $58 \%$ positivo, certamente isto se deu pela maneira como se desenrolou o estágio com mais autonomia de ação ao aluno e maior interação com o professor. $\mathrm{O}$ aluno não está suficientemente consciente de toda a problemática, pensando que o desenvolvimento de um programa como este é atribuição simples.

Ao avaliar se este estágio havia ou nāo sido mais interessante que os "demais", obtivemos $54 \%$ das respostas negativas e justificação inerente pelos próprios alunos: "todos tiveram o seu valor". As respostas positivas, quase $46 \%$ também, de forma geral, receberam justificativas do tipo:" "foi experiência nova", extrapolou a regra: hospital", "produziu conhecimentos importantes em relação à sociedade".

Como esta ainda conserva em seu currículo a habilitação médico-cinúrgica e saúde pública, para o quarto ano de graduação, um dos objetivos do programa visava produzir nos estudantes "segurança para sua opção". Comprovamos que $72 \%$ dos estudantes atingiram o esperado, os outros $28 \%$ permanecem com dúvidas, porém isso não diminui o valor do estágio para estes alunos, obviamente poderão eles optar mais conscientemente entre duas coisas já experimentadas.

O campo de estágio of erecido por essa escola de Enfermagem é essencialmente o Hospital das Clínicas de Ribeirão Preto, local onde se cuida basicamente da população carente. Quantas vezes não achamos simples dizer a um desses pacientes hospitalizados que ele necessita comer carne, muita verdura e frutas, que necessita descansar tantas horas diárias?

Ao nos depararmos com o meio em que vive esse paciente, ao conhecermos a sua habitação e realidade de sobrevivência, o choque é terrível e fica uma pergunta perdida no espaço: "o que posso fazer por ele?" É justamente isso que nós temos que aprender: por isso temos que lutar.

A tabela III mostra mais de $90 \%$ dos alunos consideram a "atuação direta com a população do bairro" no seu próprio meio ambiente, diferente da atuação com população idêntica no hospital, o que é óbvio ao se analisar o que acabamos de expor acima. 
ESPREAFICO, E. M. e Colaboradora - A Experiência do Estudante de Graduação de Enfermagem na Escola de 19 Grau Prestando Assistência Primária de Saúde. Rev. Bras. Enf.: RS, 36: 72-94 , 1983.

A tabela mostra também que a maior parte dos alunos, mais de $74 \%$, não conheciam as condições sociais da população do bairro e em seguida se comprova que grande parte (86\%) adquiriu consciência dos problemas sociais, não só locais mas gerais do país. O penúltimo dado vem apenas reforçar o 3 \% dado da tabela II.

E, finalmente, as se considerar a visita domiciliar como papel da enfermaria escolar, temse $95 \%$ das respostas afirmativas.

Concordamos com a professora Denise Cesar Homem D'EL Rey: "saúde não é algo abstrato, mas prática de vida, não se podendo separar processo educativo do ambiente da criança. A vivência das práticas de saúde, aprendidas na escola, pela criança, devem encontrar eco no lar, sendo indispensável que a escola esteja permanentemente inteirada com a família”. (D'EL Rey, 1982).

Quanto a dificuldade dos estudantes em realizar cad a u ma das atividades em si, constamos que em média, $60 \%$ não encontraram dificuldades em qualquer atividade (tabela IV) e se sentem aptos a desenvolver as mesmas após o estágio (tabela $\mathrm{V}$ ), porcentagem maior que aquela referente à formação profissional (tabela II). Ficando claro que sistematizar, coordenar e aplicar um programa como um todo sob a própria responsabilidade é muito mais sério do que realizar cada uma das atividades separadamente.

Por outro lado, aproximadamente $10 \%$ dos estudantes apresentaram grande dif iculdade em muitas atividades como exame físico das crianças, orientação do professor e funcionário em relação à saúde, educação física, lazer, conduta a tomar diante de uma criança com queixas (tabela IV).

A conduta a tomar diante de uma criança que nos solicita com determinado problema de saúde é tarefa difícil pois $67 \%$ encontraram alguma dificuldade.

Atribuimos isso ao fato de em nosso curso não sermos eficazmente preparados para solucionar problemas dessa ordem; no Hospital das Clínicas os recursos são imediatos e as resoluções, em geral, sã̃o dados pelo médico.

Conhecemos a obrigatoriedade da prática de educação física para os alunos das quatro primeiras séries do 1 ? grau contudo, observamos que isto raramente ocorre mesmo porque não existe, para tanto, profissional especializado disponível.

Estando esta prática entre as promotoras do bem estar físico e mental e sendo de uma forma de interagimos com os alunos e mais facilmente detectarmos problemas físicos e emocionais nos encarregados de realizá-la, embora alguns estudantes (7\%) referiram que poderia ser excluída do programa (tabela V).

Para que estas dificuldades fossem amenizadas foi utilizado como principal elemento de ajuda o professor do estágio (tabela VI) e foi sugerida a introdução de disciplinas específicas oficializadas no currículo de graduação cursos, aulas específicas, referências bibliográfica, palestras e treinamento (tabela VII).

A tabela VIII trata da representação dos estudantes de Enfermagem quanto à reação das crianças, mães, funcionários e prof essores mediante a presença deles.

Pensamos que esta seria uma forma de avaliar, de imediato, a repercussão que este programa de saúde produzia na comunidade escolar durante sua execução, ainda que através da interpretação dos estudantes. Estes ao responderem a questão assinalaram várias alternativas tentando abranger na resposta todos os tipos de reações que eles evidenciaram de forma generalizada, e não a mais freqüiente.

De um modo geral podemos dizer que funcionários e professores foram receptivos, uma parte deles demonstrou interesse e a outra manteve-se indiferente, porém em sua maioria sabiam quem éramos e qual a finalidade de nossa atuação no local. Enquanto mães e crianças, principalmente estas, apesar de receptivas e interessadas também apresentaram reaçōes características de estranheza, como medo agressividade e inibição; esta última pode revelar suas precárias condições sociais e econômicas.

Com a finalidade de relacionar "as experiências obtidas em estágios anteriores com o presente estágio, perguntamos se as experiências anteriores serviram de ajuda durante o desenrolar desse estágio" ou se "simplesmente não tiveram relação".

A tabela IX que trata dessa finalidade, demonstra que $72,5 \%$ dos alunos estão entre a 1 a consideração; $27,5 \%$ entre a $2 \stackrel{\text { a }}{.}$

Apesar da grande diversidade entre a atuação hospitalr e a atuação em Saúde Pública, à medida que se amplia a visão crítica tentando abranger um todo e inter-relacionando esse todo, é perf eitamente viável que todas as experiências obtidas possam ser sempre válidas e aplicáveis a diversas situações.

Assim também acreditamos que as experiências "da vida" assim como as experiências profissionais caminham juntas se completando e se aperfeiçoando.

Os $27,5 \%$ dos alunos que consideram que experiências adquiridas anteriormente não tiveram relação com este estágio pode-se explicar por eles terem se detido em alguns aspectos mais diversos 
ESPREAFICO, E. M. e Colaboradora - A Experiência do Estudante de Graduação de Enfermagem na Escola de 1 9 Grau Prestando Assistência Primária de Saúde. Rev. Bras. Enf.: RS, 36: $72-94$, 1983.

e talvez mais frequentes encontrados nesse estágio escolar, não conseguindo englobar e considerar o todo.

A tabela X se refere ao "papel do estudante de Enfermagem em uma escola de 1\% grau" de acordo com considerações deles; enfoque foi dado ao que se chama de prevenção primária (52\%), sendo que em todas as respostas de modo geral essa prevenção inclui: educação, orientação sobre aspectos como a higiene, alimentação, parasitoses, planos de imunização, saneamento, integração da escola como um todo, famílias, comunidade e primeiros socorros. Podemos, ainda, considerar como prevenção primária, a detecção precoce de problemas e aplicação de formas imediatas de resolução. Também $6,5 \%$ das respostas inclui a prevenção secundária e terciária que seriam o tratamento propriamente dito de uma determinada doença e a reabilitação.

Tudo isso requer preparação eficiente do enfermeiro e disponibilidade de outros profissionais igualmente preparados como o dentista, professor de educação física, médico etc.

Quase $13 \%$ dos estudantes consideram que após detectado um problema, a sua resolução deve ser encaminhada e quando se fizer necessário o encaminhamento a profissional especializado, ele deve manter-se inteirado à continuidade do tratamento.

Um dos papéis considerados importantes atribuído ao estudante de enfermagem foi assim mencionado por um dos estudantes: "colocar a população (via criança) que o enfermeiro não trabalha só em hospitais". E continua dizendo: "com a concretização dos programas de prevenção primária mostrar à população e ao governo a importância do elo educação-saúde".

Os papéis porpostos nesta tabela foram colocados como papéis do estudante de enfermagem na área escolar, mas obviamente representar também papéis do enfermeiro escolar.

Sentimos a necessidade de avaliar o papel social representado pela escola de enfermagem, docentes responsáveis e estudantes (tabela $\mathrm{XI}$ ), ou seja, a repercussão ou transformação que ela pode produzir na sociedade pela realização desse programa de saúde escolar.

A questão foi ampla e possibilitou enfoques diversos que foram agrupados entre aqueles que se referem a classe profissional e os referentes à sociedade em geral. Entre os primeiros estão com $20 \%$ das respostas o papel de estimulação para criação e reconhecimento de um novo campo de trabalho para o enfermeiro no Brasil.

As escolas de enfermagem necessitam se conscientizar da sua representatividade social e em entidade da classe profissional e assumir seu lugar para lutas e conquistas importantes.

Voltando à tabela, temos $4 \%$ das respostas referindo que o papel representado é de "infiltração no campo de outros profissionais".

$\mathrm{O}$ que pensar disso, o próprio estudante de enfermagem afirmando que, com um plano de saúde como tal, estamos nos infiltrando na área de outros profissionais e esses mesmos alunos respondem anteriormente que visita domiciliar não é papel do enfermeiro escolar?

Talvez seja esse um problema muito complexo mas na condição de avaliadores arriscamos algumas inferências: não será a própria escola de enfermagem que na sua maneira de formar o aluno o restringe a atividades "costumeiras" quais sejam, as hospitalares? Ou será por críticas advindas de outros profissionais ou dos próprios enfermeiros em relaçẫo ao fato? Ou ainda será a deficiente preparação dos estudantes quanto aos aspectos relacionados a este campo que os levam a tamanho desinteresse, desacreditando até mesmo da capacidade do enfermeiro para desenvolver tais projetos?

fermeiro é intensa.

Enfim, seja qual for o motivo, o certo é que a polêmica quanto à definição do papel do en-

Um aluno atribui à escola o papel de pioneira no país, quanto a esse programa de saúde escolar. Porém projeto desse tipo não é inédito, o que falta é a divulgação dos projetos anteriores.

Entre os papéis representados pela escola de Enfermagem, referentes à sociedade em geral, então, com $53 \%$ das respostas o de orientação e educação dos aspectos sociais e de saúde, de integração com a sociedade (18\%) e finalmente, o de conscientização da população quanto aos seus direitos sobre melhores condições de saúde, trabalho e vida $(2,2 \%)$. Vê-se que entre estas consideraçōes está englobado basicamente, o papel de educador.

Há necessidade do enfermeiro atuar em escolas de 1 \% grau?

As respostas foram diversas e nem sempre justificadas.

Os estudantes que responderam afinnativamente, e justificaram, alegaram ser o enfermeiro um educador e orientador de saúde; que o enfermeiro deve atuar à nível de prevenção primária; que esta atuação serviria de vínculo entre escola e comunidade e se faz necessário por não haver profissionais na área, o que generalizado não é verdade, pois existem muitos trabalhos de médicos, dentistas e psicólogos nesta área; isto demonstra a falta de conhecimento do aluno sobre a situação. Talvez por falta da própria programação proposta que poderia educar mais, a atual situação da saúde escolar, principalmente no país. 
Dos dois alunos que consideram dispensável a atuação do enfermeiro na escola, um alega não ser necessária a sua presença diariamente após organizado e encaminhado o programa, o que se faz totalmente inviável tendo em vista os aspectos já discutidos no decorrer do trabalho.

A tabela XIII engloba as perspectivas "dos estudantes de Enfermagem em relaçāo à escola de 1. grau como campo de trabalho para o enfermeiro". A questão foi colocada aos estudantes de forna aberta e proporcionou interpretações variadas, com $13 \%$ das respostas enfocando as perspectivas individuais e $87 \%$ perspectivas gerais, sendo que 6 alunos não responderam a questão.

Essa evasão do asssunto e disparidade de respostas podem ser reflexos da ininteligibilidade da pergunta ou da própria falta de interesse e conscientização do estudante quanto à seriedade dessa avaliação.

As perspectivas individuais são adversas, quase $8 \%$ pretende se enquadrar à enfermagem hospitalar e mais de $5 \%$ pretende atuar no campo de saúde escolar.

Entre as perspectivas gerais há várias respostas incoerentes, confirmando o que já foi dito há pouco...

As mais significativas qualitativamente são: bom campo de trabalho desde que o governo leve a sério esta proposta da enfermagem e ofereça empregos a enfermeiros aptos a atuar neste campo ( $8 \%)$, mas do ponto de vista financeiro (3\%), ótimas perspectivas (5\%), pois este é um campo de trabalho que mais proporciona autonomia e liberdade de ação ao enfermeiro.

\section{CONCLUSÃO}

Concluímos que a presente programação de saúde escolar, ofereceu aos estudantes de enfermagem importante experiência e aprendizado e, pelo menos, início da formação de uma consciência crítica em torno da problemática social do país. E, mais àqueles que voltam seus interesses, essencialmente, á área hospitalar, a execução dessa programação representou, talvez, a única oportunidade de conhecer alguns dos aspectos gerais da assistência primária. ca no aluno.

Esta á, o "papel" da graduação : abrir perspectivas e despertar interesse e consciência críti-

Quem se colocar estático diante do mundo presente, está a cada instante regredindo. Este é o "papel" do enfermeiro, estar consciente e seguro das suas atividades e participar ativamente seja qual for a sua prioridade de trabalho, de forma a ampliar e assegurar novas metas de atuação.

Evidenciamos, no dia a dia, que o país se encontra com número muito grande de profissionais em todas as áreas, com atuação grandemente deficiente ou não consciente das suas próprias incumbências, sendo provavelmente, o maior responsável por isso o deficiente ensino a que é submetido desde a base até a formação profissional, dentre outros fatores de ordem política, econômica e social.

O profissional necessita de uma preparação específica e profunda sobre a área na qual atuará, a fim de aumentar a bagagem teórica e experimental, o que lhe proporciona maior segurança, autonomia e facilidades em encontrar alternativas para a resolução de problemas relativos ao exercício profissional.

Está aberta a questão da escola de 1ㅇ grau como "eminente campo" de atuação do Enfermeiro, no Brasil. Tendo sido o presente trabalho realizado à maneira de um estudo de caso, não é pas sível de generalização necessitando de trabalhos complementares.

TABELA I - Experiências gos estudantes de enfermagem em escolas de 10 grau antes desse estágio.

\begin{tabular}{ccccc}
\hline \multicolumn{2}{c}{ SIM } & TOTAL & NĀO & TOTAL \\
\hline Assistência de Saúde + Magistério & & & \\
\hline 2 & 3 & 5 & 37 & 42 \\
$(4,76 \%)$ & $(7,14 \%)$ & $(11,9 \%)$ & $(88,1 \%)$ & $(100 \%)$ \\
\hline
\end{tabular}

NOT A: Uma resposta afirmativa, não expecifica a experiência. Uma resposta se refere a um mês de atuação no Projeto Rondon; a outra se refere a orientações a alunos de uma escola rural, aos sábados. 
ESPREAFICO, E. M. e Colaboradora - A Experiência do Estudante de Graduação de Enfermagem na Escola de 10 Grau Prestando Assistência Primária de Saúde. Rev. Bras. Enf.: RS, 36: $72-94$, 1983.

TABELA II - Representatividade do estágio na escola de 1 o grau, para os alunos de graduação do 3 ? ano de enfermagem.

\begin{tabular}{|c|c|c|c|}
\hline \multirow{2}{*}{ CONTRIBUIÇĀO DO ESTẢGIO } & \multicolumn{2}{|c|}{ RESPOSTAS } & \multirow{2}{*}{ TOTAL } \\
\hline & SIM & $\mathrm{NA \overline {O }}$ & \\
\hline Oportunidade de aprendizado & $\begin{array}{c}42 \\
(97,76 \%)\end{array}$ & $\begin{array}{c}1 \\
(2,33 \%)\end{array}$ & $\begin{array}{c}43 \\
(100 \%)\end{array}$ \\
\hline Experiências importantes & $\begin{array}{c}39 \\
(90,70 \%)\end{array}$ & $\begin{array}{c}4 \\
(9,30 \%)\end{array}$ & $\begin{array}{c}43 \\
(100 \%)\end{array}$ \\
\hline $\begin{array}{l}\text { Idéias para planejar trabalhos em escolas de } 19 \\
\text { grau. }\end{array}$ & $\begin{array}{c}40 \\
(93,02 \%)\end{array}$ & $\begin{array}{c}3 \\
(6,98 \%)\end{array}$ & $\begin{array}{c}43 \\
(100 \%)\end{array}$ \\
\hline $\begin{array}{l}\text { Formação suficiente de como agir em assistên- } \\
\text { cia primária em escolas de } 1 \% \text { grau. }\end{array}$ & $\begin{array}{c}25 \\
(58,14 \%)\end{array}$ & $\begin{array}{c}18 \\
(41,86 \%)\end{array}$ & $\begin{array}{c}43 \\
(100 \%)\end{array}$ \\
\hline O estágio foi mais interessante que os demais. & $\begin{array}{c}17 \\
(45,95 \%)\end{array}$ & $\begin{array}{c}20 \\
(54,05 \%)\end{array}$ & $\begin{array}{c}37 * \\
(100 \%)\end{array}$ \\
\hline Complementou os demais estágios & $\begin{array}{c}37 \\
(86,05 \%)\end{array}$ & $\begin{array}{c}6 \\
(13,95 \%)\end{array}$ & $\begin{array}{c}43 \\
(100 \%)\end{array}$ \\
\hline Contribui para a comunidade local & $\begin{array}{c}39 \\
(90,70 \%)\end{array}$ & $\begin{array}{c}4 \\
(9,30 \%)\end{array}$ & $\begin{array}{c}43 \\
(100 \%)\end{array}$ \\
\hline $\begin{array}{l}\text { Condições para optar com segurança quanto à } \\
\text { habilitação no } 4 \text { ? ano de graduação. }\end{array}$ & $\begin{array}{c}31 \\
(72,09 \%)\end{array}$ & $\begin{array}{c}12 \\
(27,91 \%)\end{array}$ & $\begin{array}{c}43 \\
(100 \%)\end{array}$ \\
\hline
\end{tabular}

*06 alunos responderam que não havia diferenças.

TABELA III - Parecer dos alunos em relação a atuação direta com a população do bairro por meio de visitas domiciliares.

\begin{tabular}{|c|c|c|c|}
\hline \multirow{2}{*}{ ITENS PROPOSTOS } & \multicolumn{2}{|c|}{ ALTERNATIVAS } & \multirow{2}{*}{ TOTAL } \\
\hline & SIM & NĀO & \\
\hline $\begin{array}{l}\text { Se é semelhante à atuação no hospital com a } \\
\text { mesma população. }\end{array}$ & $\begin{array}{c}4 \\
(9,76 \%)\end{array}$ & $\begin{array}{c}37 \\
(90,24 \%)\end{array}$ & $\begin{array}{l}41^{*} \\
(100 \%)\end{array}$ \\
\hline $\begin{array}{l}\text { As condições de Saúde, higiene, educacional e } \\
\text { econômica dessa populą̧ão eram desconhecidas. }\end{array}$ & $\begin{array}{c}11 \\
(25,58 \%)\end{array}$ & $\begin{array}{c}32 \\
(74,42 \%)\end{array}$ & $\begin{array}{c}43 \\
(100 \%)\end{array}$ \\
\hline $\begin{array}{l}\text { O estágio deu condições de reconhecer a reali- } \\
\text { dade e gravidade dos problemas sociais do país. }\end{array}$ & $\begin{array}{c}37 \\
(86,05 \%)\end{array}$ & $\begin{array}{c}6 \\
(13,95 \%)\end{array}$ & $\begin{array}{c}43 \\
(100 \%)\end{array}$ \\
\hline $\begin{array}{l}\text { Ofereceu preparo para trabalhos semelhantes } \\
\text { em escola e comunidade. }\end{array}$ & $\begin{array}{c}40 \\
(93,02 \%)\end{array}$ & $\begin{array}{c}3 \\
6,98 \%)\end{array}$ & $\begin{array}{c}43 \\
(100 \%)\end{array}$ \\
\hline Visita domiciliar é papel da enfermeira escolar. & $\begin{array}{c}41 \\
(95,35 \%)\end{array}$ & $\begin{array}{c}2 \\
(4,65 \%)\end{array}$ & $\begin{array}{c}43 \\
(100 \%)\end{array}$ \\
\hline
\end{tabular}

* 2 alunos não responderam. 
TABELA IV - Grau de dificuldade "dos estudantes diante das atividades de propostas no éstágio.

\begin{tabular}{|c|c|c|c|c|c|}
\hline \multirow{2}{*}{ ATIVIDADES } & \multicolumn{4}{|c|}{ GRAU DE DIFICULDADE } & \multirow{2}{*}{ TOTAL } \\
\hline & 0 & 1 & 2 & 3 & \\
\hline Visita Domiciliária. & $\begin{array}{c}28 \\
(65,11 \%)\end{array}$ & $\begin{array}{c}10 \\
(23,26 \%)\end{array}$ & $\begin{array}{c}5 \\
(11,63 \%)\end{array}$ & $\begin{array}{c}0 \\
(0)\end{array}$ & $\begin{array}{c}43 \\
(100 \%)\end{array}$ \\
\hline Aulas sobre educação e hábitos à saúde. & $\begin{array}{c}26 \\
(66,66 \%)\end{array}$ & $\begin{array}{c}9 \\
(23,08 \%)\end{array}$ & $\begin{array}{c}4 \\
(10,26 \%)\end{array}$ & $\begin{array}{c}0 \\
(0)\end{array}$ & $\begin{array}{c}39 \\
(100 \%)\end{array}$ \\
\hline Exame físico das crianças. & $\begin{array}{c}18 \\
(45 \%)\end{array}$ & $\begin{array}{c}13 \\
(32,50 \%)\end{array}$ & $\begin{array}{c}6 \\
(15 \%)\end{array}$ & $\begin{array}{c}3 \\
(7,50 \%)\end{array}$ & $\begin{array}{c}40 \\
(100 \%)\end{array}$ \\
\hline $\begin{array}{l}\text { Orientação à professores e funcionários } \\
\text { em relação à saúde. }\end{array}$ & $\begin{array}{c}11 \\
(40,74 \%)\end{array}$ & $\begin{array}{c}7 \\
(25,93 \%)\end{array}$ & $\begin{array}{c}6 \\
(22,22 \%)\end{array}$ & $\begin{array}{c}3 \\
(11,11 \%)\end{array}$ & $\begin{array}{l}27 \\
(100 \%)\end{array}$ \\
\hline $\begin{array}{l}\text { Encaminhamento de crianças com pro- } \\
\text { blemas. }\end{array}$ & $\begin{array}{c}28 \\
(70 \%)\end{array}$ & $\begin{array}{l}10 \\
(2,5 \%)\end{array}$ & $\begin{array}{c}1 \\
(2,5 \%)\end{array}$ & $\begin{array}{c}1 \\
(2,5 \%)\end{array}$ & $\begin{array}{c}40 \\
(100 \%)\end{array}$ \\
\hline $\begin{array}{l}\text { Conduta diante de uma criança com } \\
\text { queixas de saúde. }\end{array}$ & $\begin{array}{c}13 \\
(33,33 \%)\end{array}$ & $\begin{array}{c}19 \\
(48,72 \%)\end{array}$ & $\begin{array}{c}4 \\
(10,26 \%)\end{array}$ & $\begin{array}{c}3 \\
(7,69 \%)\end{array}$ & $\begin{array}{c}39 \\
(100 \%)\end{array}$ \\
\hline Educação Física & $\begin{array}{c}28 \\
(65,12 \%)\end{array}$ & $\begin{array}{c}7 \\
(16,28 \%)\end{array}$ & $\begin{array}{c}2 \\
(4,65 \%)\end{array}$ & $\begin{array}{c}6 \\
(13,95 \%)\end{array}$ & $\begin{array}{c}43 \\
(100 \%)\end{array}$ \\
\hline Lazer & $\begin{array}{c}28 \\
(71,79 \%)\end{array}$ & $\begin{array}{c}7 \\
(17,95 \%)\end{array}$ & $\begin{array}{c}0 \\
(0)\end{array}$ & $\begin{array}{c}4 \\
(10,26 \%)\end{array}$ & $\begin{array}{c}39 \\
(100 \%)\end{array}$ \\
\hline
\end{tabular}

*o grau de dificuldade é graduado da seguinte forma:

$0=$ ausência de dificuldade

$1=$ pequena dificuldade

$2=$ média dificuldade

3 = grande dificuldade

*a variação no total de alunos nas várias atividades é devido a não realização das mesmas. 
TABELA V - Apreciação do aluno quanto às atividades que constam da tabela IV.

\begin{tabular}{lcccc}
\hline \multicolumn{1}{c}{ QUESTŌES PROPOSTAS } & \multicolumn{3}{c}{ RESPOSTAS } & \multirow{2}{*}{ TOTAL } \\
\cline { 2 - 3 } & SIM & \pm & NÃO & 43 \\
\hline $\begin{array}{l}\text { É importante que o enfermeiro esteja prepa- } \\
\text { rado para essas atividades. }\end{array}$ & 40 & - & 3 & $(93,02 \%)$ \\
$\begin{array}{l}\text { O estudante se encontra apto a desenvolver } \\
\text { as mesmas, após o estágio. }\end{array}$ & 33 & 4 & $(6,98 \%)$ & $(100 \%)$ \\
\end{tabular}

TABELA VI - Elementos que ajudaram os estudantes a suprimir as suas dificuldades diante das atividades inerentes à tabela III

Professor de estágio

Professores da escola

Colegas

Referências bibliográficas

Nota: Os alunos assinalaram mais de uma alternativa. 
ESPREAFICO, E. M. e Colaboradora - A Experiência do Estudante de Graduação de Enfermagem na Escola de 19 Grau Prestando Assistência Primária de Saúde. Rev. Bras. Enf.: RS, 36: 7.2.94, 1983.

TABELA VII - Sugestões dos alunos como preparação para as atividades inerentes a tabela III.

Cursos

Disciplinas específicas oficializadas no currículo de graduação

Referências bibliográficas

Aulas

Palestras *

1

( $1,15 \%)$

Treinamento*

1

Nota: Os alunos assinalaram mais de uma alternativa.

* : Essas duas sugestões não estavam explícitas na questão, foram incluídas por um aluno. 
ESPREAFICO, E. M. e Colaboradora - A Experiência do Estudante de Graduação de Enfermagem na Escola de 10 Grau Prestando Assistência Primária de Saúde. Rev. Bras. Enf.: RS, 36: $72-94$, 1983.

TABELA VIII - Representação dos estudantes de enfermagem quanto à reação das crianças, mães, funcionários e professores, diante da atuação deles na escola e comunidade.

\begin{tabular}{|c|c|c|c|}
\hline POSSIVEEIS REAÇÕES OCORRIDAS & CRIANÇAS & MÃES & $\begin{array}{l}\text { FUNCIONÅRIOS E } \\
\text { PROFESSORES }\end{array}$ \\
\hline Indiferença & $\begin{array}{c}3 \\
(1,89 \%)\end{array}$ & $\begin{array}{c}4 \\
(6,56 \%)\end{array}$ & $\begin{array}{c}10 \\
(18,87 \%)\end{array}$ \\
\hline Receptividade & $\begin{array}{c}38 \\
(23,90 \%)\end{array}$ & $\begin{array}{c}27 \\
(44,26 \%)\end{array}$ & $\begin{array}{c}28 \\
(52,83 \%)\end{array}$ \\
\hline Agressividade & $\begin{array}{c}7 \\
(4,40 \%)\end{array}$ & $\begin{array}{c}1 \\
(1,64 \%)\end{array}$ & - \\
\hline Alegria & $\begin{array}{c}28 \\
(17,61 \%)\end{array}$ & - & $\begin{array}{c}1 \\
(1,89 \%)\end{array}$ \\
\hline Interesse & $\begin{array}{c}36 \\
(22,64 \%)\end{array}$ & $\begin{array}{c}16 \\
(26,23 \%)\end{array}$ & $\begin{array}{c}11 \\
(20,75 \%)\end{array}$ \\
\hline Medo & $\begin{array}{c}8 \\
(5,03 \%)\end{array}$ & $\begin{array}{c}2 \\
(3,28 \%)\end{array}$ & \\
\hline Inibição & $\begin{array}{c}13 \\
(8,18 \%)\end{array}$ & $\begin{array}{c}9 \\
(14,75 \%)\end{array}$ & $\begin{array}{c}1 \\
1,89 \%)\end{array}$ \\
\hline Carinho & $\begin{array}{c}26 \\
(16,35 \%)\end{array}$ & $\begin{array}{c}2 \\
(3,28 \%)\end{array}$ & $\begin{array}{c}2 \\
(3,77 \%)\end{array}$ \\
\hline \multirow[t]{2}{*}{ TOTAIS } & 159 & 61 & 53 \\
\hline & $(100 \%)$ & (100\%) & (100\%) \\
\hline
\end{tabular}

Nota: Os alunos responderam a mais de uma alternativa.

TABELA IX - Relação entre as experiências já obtidas em outros estágios com o presente estágio. 
TABELA X - O papel do estudante de enfermagem na Escola de 1 ? grau.

\begin{tabular}{|c|c|}
\hline PAPÉIS PROPOSTOS & No DE RESPOSTAS \\
\hline Prevenção primária & $40(51,95 \%)$ \\
\hline Prevenção secundária & $5(6,49 \%)$ \\
\hline Prevenção terciária & $5(6,49 \%)$ \\
\hline Lazer de forma a estimular a parte motora e intelectual & $14(18,18 \%)$ \\
\hline $\begin{array}{l}\text { Auxiliar na resolução dos problemas detectados, mesmo quando se faz } \\
\text { necessário encaminhar a profissional especializado. }\end{array}$ & $10(12,90 \%)$ \\
\hline $\begin{array}{l}\text { Colocar à população (via criança) que o enfermeiro não trabalha só no } \\
\text { hospital. }\end{array}$ & $1(1,30 \%)$ \\
\hline $\begin{array}{l}\text { Com a concretização do programa de prevenção primária mostrar à po- } \\
\text { pulação e ao governo a importância do elo "Educação-Saúde". }\end{array}$ & $1(1,30 \%)$ \\
\hline $\begin{array}{l}\text { Participar na preparação da merenda escolar e colaborar na variação do } \\
\text { cardápio (dentro das possibilidades) }\end{array}$ & $1(1,30 \%)$ \\
\hline TOTAL & $77(100 \%)$ \\
\hline
\end{tabular}

"Em todas as respostas de forma geral, em prevenção primária, inclui-se : educação, orientação sobre as pectos como higiene, alimentação, parasitoses, plano de imunização, saneamento e integração da escola, como um todo, famílias e comunidades, primeiros socorros e orientação de professores e funcionários. 
ESPREAFICO, E. M. e Colaboradora - A Experiência do Estudante de Graduação de Enfermagem na Escola de 10 Grau Prestando Assistência Primária de Saúde. Rev. Bras. Enf.: RS, 36: $72-94$, 1983.

TABELA XI - Papel social representado pela Escola de Enfernnagem, Docentes Responsáveis e Estudantes, pela realização desse programa de saúde escolar.

PAPÉIS ATRIBUIIDOS

No DE RESPOSTAS

\section{RELATIVOS À CLASSE PROFISSIONAL}

De estimulação para a criação e reconhecimento de novo campo de trabalho para o Enfermeiro no Brasil.

De infiltração no campo de outros profissionais

De pioneiro no país

\section{RELATIVOS Ȧ SOCIEDADE}

"De conscientização da população quanto aos seus direitos sobre melhores condições de saúde, trabalho e vida".

1

De integração com a sociedade

De orientação e educação nos aspectos sociais de saúde. 
TABELA XII - Considerações do estudante quanto à necessidade da atuação do enfermeiro em escolas de 1 ? grau.

\section{NECESSÅRIA}

Como educador e orientador de saúde

A nível de prevenção primária

Como vínculo entre a escola e a comunidade

Se juntamente com outros profissionais

Porque não há profissionais na área

\section{MAIS OU MENOS}

Não é necessária a presença do enfermeiro diariamente após "posto em prática" o programa

NOTA: um aluno não respondeu. nausência de justificativas. 
ESPREAFICO, E. M. e Colaboradora A Experiência do Estudante de Graduação de Enfermagem na Escola de 10 Grau Prestando Assistência Primária de Saúde. Rev. Bras. Enf.: RS, 36: $72-94$, 1983.

TABELA XIII - Perspectivas em relação à escola de $1^{\text {O }}$ grau como campo de trabalho para o profissional de enfermagem.

\section{PERSPECTIVAS INDIVIDUAIS}

Pretende se enquadrar em enfermagem hospitalar

Pretende atuar neste campo

\section{PERSPECTIVAS GERAIS}

Novo campo de atuação

Promissor à medida que o enfermeiro realize um bom trabalho.

Oportunidade para um maior vínculo entre a escola e a família.

Bom campo de trabalho

Bom desde que o governo leve a sério esta proposta de trabalho da enfermagem e ofereça empregos a enfermeiros aptos a atuar neste campo.

Más, do ponto de vista financeiro

Que o enfermeiro consiga ef etivamente a tuar em prevenção primária

E bom pois atua junto à comunidade

Otima pois proporciona autonomia aos profissionais em seu campo de ação.

Seriam melhores se houvesse especialização na área

Que o plano de enfermagem escolar se estenda à todas as escolas

Boas desde que integrada a outros profissionais

Nota: 6 ahunos não responderam a questão

1 ahuo mencionou mais de uma resposta 
ESPREAFICO, E. M. e Colaboradora - A Experiência do Estudante de Graduação de Enfermagem na Escola de 19 Grau Prestando Assistência Primária de Saúde. Rev. Bras. Enf.: RS, 36:

\section{SUMMARY}

The work analyzes an experience of forty-three students, from sixty-five, who attend the $5^{\text {th }}$ semester of graduation in 1982, in a nursing school - USP, Ribeirão Preto, composed by students of the neighborhood, with a precary socialeconomic level; making assistance of health to the students, through their environment: school, family and community. questions.

To avalue the experience of those students, we used a questionnaire with eighteen

The analysis of the results shows the great importance to inclue similar programs in the apprenticeship, make the student conscious of the situation, and open fields to the nurse actuation.

\section{REFERÊNCIAS BIBLIOGRĀFICAS}

STOFFEL, Floriano - Ortogênese do Escolar, Evolução e conceituação. Pediatria Moderna, Rio de Janeiro 7 (1): $28-48$, abril 1972.

TRINDADE, José Coimbra - A saúde escolar e seus novos rumos Pediatria Moderna, Rio de Janeiro 7 (1): 8 - 27, abril 1972 .

STOFFEL, Floriano - Preparo dos integrantes do Serviço de Saúde Escolar. Pediatria Moderna, Rio de Janeiro 9 (5): $37-52$ julho 1974 .

CENTRO DE DEFESA DA QUALIDADE DE VIDA - A Situação da Criança no Brasil 2ª ed. Rio de Janeiro, Ilha 1980.

ODA, S. Dorothy - El papel de la Enfermera de Salud Comunitária em los sistemas escolares. In: Enfermeira de Salud Comunitária. OMS 1977, p. 297-311.

LOIS FRELS, R.N.-M.A.National Survey, School Nurse Certification, The Journal of School Health Kent 44 (6): 340-341 june 1974.

PERNETTA, Cesar - Alimentação do Pré-escolar e do Escolar, In: Alimentação da Criança 7 a ed., São Paulo, FEBP 1980 p. 237-243.

SCHMIDT, Cheryl Klouzal - Public Schools as a Clinical Experience for Nursing Students, The Journal of School Health Kent 51 (8): $492-495$ september 1981.

MELO, Guiomar N. - As condições Intra Escolares na Determinação da Seletividade no Ensino de 1\% Grau, Um Problema de Pesquisa, In: Seletividade Sócio Econômico no Ensino de 1 ? Grau. ANPED Rio de Janeiro, 1981 p. 15-25.

D'EL REY, Denise Cesar Homem - Pesquisa Ajuda a Educação em Saúde USP informações - São Paulo 112:6. 1982. 
ESPREAFICO, E. M. e Colaboradora - A Experiência do Estudante de Graduação de Enfermagem na Escola de 19 Grau Prestando Assistência Primária de Saúde. Rev. Bras. Enf.: RS, 36: 72-94 , 1983.

\section{ANEXO I}

\section{UNIDADE DE ENFERMAGEM PEDIĀTRICA}

Assistência de Enfermagem em escolas de 1 ? e 20 grau (Higiene Escolar)

CARGA HORẢRIA - 40 horas semanais

NUMERO DE ALUNOS - 65

NUMERO DE GRUPOS - 06

NUMERO DE ALUNOS POR GRUPO - 10 a 11

ALUNOS MONITORES - 07

LOCAL DE ESTĀGIO - Escola de 10 grau "Prof. Rafel Leme Franco"

DOCENTES RESPONSĀ VEIS - Maria das Graças C. Ferriani

DURAÇÃO DO CURSO - 08 semanas

- Maria A parecida Todechi Cano

PERYODO DO CURSO - 1 \% de março a 26 de junho.

HORĀRIO - Manhã $-2{ }^{a}$ a a $6^{\text {a }}$. feira das 7:30 às 12:00 horas

- Tarde $-2^{\mathrm{a}}, 3^{\mathrm{a}}, 5^{\mathrm{a}}$ e e $6^{\mathrm{a}}$. feira das $13: 30$ às $17: 00$ horas

MÉTODO

Seminários, Discussões em grupo, Estudos de casos, Demonstrações, Trabalho em grupo de estágio e Pesquisa bibliográfica.

\section{ATIVIDADES DISCENTES}

Participação em grupo de discussão, seminários, trabalhos individuais e em grupos.

Dentro da Unidade de Enfermagem Pediátrica, a parte será avaliada através de um relatório final onde conste o planejamento e execução dos programas propostos.

\section{OBJETIVOS GERAIS}

Desenvolver dentro da disciplina de Enfermagem Pediátrica, um programa de Assistência ao Escolar que leve o Enfermeiro a interagir com a criança como membro de uma família, na escola, na comunidade.

\section{CONTEUDO TEÓRICO PRÁTICO}

\section{Unidade I}

1. Conhecimento e interação do sistema escolar

2. Interação com os pais dos alunos

3. Conhecimento e interação com a comunidade na qual a escola se encontra inserida.

4. Avaliação do estado de saúde das crianças e dar assistência em nível de prevenção Primária à Saúde através de:

- Exame físico do Escolar e comparação com os parâmetros normais de crescimento e desenvolvimento infantil.

- Levantamento das necessidades básicas quanto:
a) Nutrição
b) Higiene Dentária
c) Higiene Corporal
d) Imuniz ação
s) Lazer

5. Planejamento e Execução de Visitas Domiciliares às Famílias com os seguintes objetivos:

- Avaliação do Saneamento Básico

- Avaliação das condições sócio-econômicas 
6. Assistência de Enfermagem à Criança com:

- Febre

- Diarréia

- Vômito

- Piodermite

- Escabiose

- Verminose

- Pediculose

7. Encaminhamento das crianças com problema de saúde para os Postos de Atendimento da Comunidade.

\section{Unidade II}

1. Planejamento e Execução de programas para os alunos como:

- Educação Sexual

- Alcoolismo

- Tóxicos

2. Assessoria aos professores na Educação Física para os alunos da $1 \stackrel{\text { a à }}{4}{ }^{0}$ série.

3. Assessoria aos pelotões de saúde.

4. Planejar, organizar e executar cursos sobre higiêne e nutrição para o pessoal responsável pela merenda escolar.

5. Promoção de campanhas e concursos de saúde.

6. Participação nas reuniões de Pais e Mestres.

7. Colaborar com as Psicólogas da Escola de Enfermagem de Ribeirão Preto - USP para formação e condução dos grupos de alunos com problemas de comportamento na escola.

8. Encaminhamento dos alunos com dificuldade motora para o convênio de Psiquiatria da Escola de Enfermagem de Ribeirão Preto - USP. 
ESPREAFICO, E. M. e Colaboradora - A Experiência do Estudante de Graduação de Enfermagem na Escola de 10 Grau Prestando Assistência Primária de Saúde. Rev. Bras. Enf.:RS, 36: 72-94 , 1983.

\section{ANEXO II}

\section{Q U E S T I O N ÅR I O}

Essas questões referem à sua experiência, quanto a atuação na Escola de 1 ọ grau Prof. Rafael Leme Franco, como estudante de Enfermagem, prestando assistência primária, de saúde, à comunidade.

NOME:

1. Você já teve alguma experiência em escolas de 1 ? grau antes deste estágio?
( ) $\operatorname{sim}$
( ) não

Especifique:

2. O estágio na Escola Estadual de Primeiro Grau Prof. Rafael Leme Franco:

a) representou uma oportunidade de aprendizagem? ( ) sim ( ) não

b) significou experiências importantes? ( ) sim ( ) não

c) foi oportunidade de ensinar hábitos de higiene e saúde? ( ) sim （ ） não

d) despertou seu interesse para o cumprimento das atividades do programa?

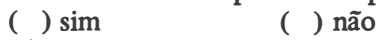

e) deu idéias de como planejar trabalhos em escolas de 19 grau?
( ) $\operatorname{sim}$
( ) não

f) deu formação, suficiente de como agir a nível de assistência primária de Enfermagem, em escolas de 1 ? grau?
( ) sim
( ) não

g) foi mais interessante que os demais estágios realizados?
( ) sim
( ) não

h) complementou os demais estágios realizados?

( ) sim ( ) não

i) você acha que contribuiu para a comunidade local?
( ) sim
( ) não. Justifique a partir de dados concretos:

2. A atuação direta com a população do bairro por meio de visitas domiciliares:

a) é semelhante à atuação no hospital com a mesma população?

( ) sim

( ) não

b) as condições de saúde, higiene educacional e econômica dessa população eram desconhecidas por você?
( ) $\operatorname{sim}$
( ) não

c) o estágio deu condições de reconhcer a realidade e gravidade dos problemas sociais do nosso país?
( ) $\operatorname{sim}$
( ) não

d) após essa experiência você se sente mais preparada para os trabalhos semelhantes em escolas, comunidade e com a realidade que vivenciou?
( ) sim
( ) não

e) a visita domiciliar é papel da Enfermaria escolar?

( ) sim ( ) não. Se responder não justifique:

3. Dos programas estabelecidos, quais (ou qual), você teve maior dificuldade em realizar:

OBS: Aos itens dessa questão deve ser atribuído notas de zero a três, que significam:

$$
\begin{aligned}
& 0=\text { não houve dificuldade } \\
& 1=\text { pequena dificuldade } \\
& 2=\text { média dificuldade } \\
& 3=\text { grande dificuldade }
\end{aligned}
$$

a) visitas domiciliares ( )

b) aulas expositivas ou sob forma de dramatização sobre educação e hábitos à saúde de forma geral, como, higiene corporal, higiene bucal, educação sexual, parazitoses, etc. ( ) 
c) exame físico das crianças ( )

d) orientação a professores e funcionários em relação à saúde ( )

e) encaminhamento dos alunos com problema de saúde para instituições de recursos da comunidade ( )

f) conduta a tomar diante de uma criança com problema de saúde ( )

g) educação física ( )

h) atividades de lazer para os alunos ( )

OBS: se algumas dessas atividades, acima, você não teve oportunidade de realizar ou se realizou outras diferentes, especifique-as.

4) Quais das atividades exigiu de você, maior preparo?

5) Considera importante que a enfermeira esteja preparada nos aspectos referentes a essas atividades?

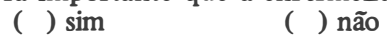

6) Você se considera, agora, em condições de desenvolver tais atividades?

$$
\begin{array}{ll}
\text { ( ) } \operatorname{sim} \text { ( ) não } & 0 \\
&
\end{array}
$$

7) Quem a(o) ajudou nas dificuldades encontradas durante a realização de tais atividades?
a) prof essor do estágio ( )
b) professor da escola ( )
c) colegas ( )
d) referências bibliográficas ( )
e) outras ( )

Especifique:

8) O que você sugere como preparação para essas atividades?
a) cursos ( )
b) disciplinas específ icas oficializadas, no currículo de graduação ( )
c) referências bibliográficas ( )
e) outras ( )

Especifique:

9) Qual a reação das crianças quanto à presença dos estudantes e profissionais de Enfermagem?
a) indiferença ( )
b) receptividade ( )
c) agressividade ( )
d) alegria ( )
e) interesse ( )
f) medo ( )
g) inibição ( )
h) carinho ( ) 
ESPREAFICO, E. M. e Colaboradora - A Experiência do Estudante de Graduação de Enfermagem na Escola de 19. Grau Prestando Assistência Primária de Saúde. Rev. Bras. Enf.: RS, 36: 72-94 , 1983.

Obs: Para as duras questões seguintes, use os itens acima, especificando apenas, a letra de ordem de cada um, que você se referir.

10) Qual a reação da mãe ou do responsável pelo aluno, quanto à sua presença (em visitas domiciliares ou na escola)?

11) Qual a reação dos professores e funcionários da escola quanto à presença dos estudantes e profissionais de Enfermagem?

12) As esperiências que você teve nos outros estágios da Escola de Enfermagem:

a) ajudou-o neste estágio ( )

b) não teve relação com este estágio ( )

c) outras resposta ( )

Justifique:

13) Essa experiência de, assistência primária à comunidade, que você teve nesse estágio, d o 3 ̣̣ ano de graduação, deu-the segurança para optar quanto a sua habilitação no 4 ? ano de graduação?

$$
\text { ( ) } \operatorname{sim} \quad(\text { ) não }
$$

14) Qual o papel do estudante de enfermagem na Escola de 1 . grau?

15) Você considera necessária a atuação do Enfermeiro na escola de 1\% grau?

$$
\text { ( ) sim ( ) não }
$$

Justifique:

16) Qual o papel social representado pela Escola de Enfermagem, docentes responsáveis e estudantes, pela realização desse tipo de trabalho?

17) Quais suas perspectivas, em relação a escola de 1 ? grau, como campo de trabalho para o profissional de Enfermagem?

18) Qual seu interesse em atuar nesse campo? 